\title{
Arctic Tundra Vegetation Functional Types Based on Photosynthetic Physiology and Optical Properties
}

\author{
Karl Fred Huemmrich, John A. Gamon, Craig E. Tweedie, Petya K. Entcheva Campbell, Member, IEEE, \\ David R. Landis, and Elizabeth M. Middleton
}

\begin{abstract}
Non-vascular plants (lichens and mosses) are significant components of tundra landscapes and may respond to climate change differently from vascular plants affecting ecosystem carbon balance. Remote sensing provides critical tools for monitoring plant cover types, as optical signals provide a way to scale from plot measurements to regional estimates of biophysical properties, for which spatial-temporal patterns may be analyzed. Gas exchange measurements were collected for pure patches of key vegetation functional types (lichens, mosses, and vascular plants) in sedge tundra at Barrow AK. These functional types were found to have three significantly different values of light use efficiency (LUE) with values of $0.013 \pm 0.001,0.0018 \pm 0.0002$, and $0.0012 \pm 0.0001 \mathrm{~mol} \mathrm{C} \mathrm{mol}^{-1}$ absorbed quanta for vascular plants, mosses and lichens, respectively. Discriminant analysis of the spectra reflectance of these patches identified five spectral bands that separated each of these vegetation functional types as well as nongreen material (bare soil, standing water, and dead leaves). These results were tested along a $100 \mathrm{~m}$ transect where midsummer spectral reflectance and vegetation coverage were measured at one meter intervals.

Along the transect, area-averaged canopy LUE estimated from coverage fractions of the three functional types varied widely, even over short distances. The patch-level statistical discriminant functions applied to in situ hyperspectral reflectance data collected along the transect successfully unmixed cover fractions of the vegetation functional types. The unmixing functions, developed from the transect data, were applied to $30 \mathrm{~m}$ spatial resolution Earth Observing-1 Hyperion imaging spectrometer data to examine variability in distribution of the vegetation functional types for an area near Barrow, AK. Spatial variability of LUE was derived from the observed functional type distributions. Across this landscape, a fivefold variation in tundra LUE was observed. LUE calculated from the functional type cover fractions was also correlated to a spectral vegetation index developed to detect vegetation chlorophyll content. The concurrence of these alternate methods suggest that hyperspectral remote sensing can distinguish functionally distinct vegetation types and can be used to develop regional estimates of photosynthetic LUE in tundra landscapes.
\end{abstract}

Manuscript received February 23, 2012; revised August 03, 2012; accepted February 27, 2013. Date of publication April 24, 2013; date of current version May 13, 2013. Funding for the field component of this study was provided by IARC to J. A. Gamon and K. F. Huemmrich through the Desert Research Institute, Reno, Nevada, USA.

K. F. Huemmrich and P. K. E. Campbell are with the University of Maryland Baltimore County, Goddard Space Flight Center, Greenbelt, MD 20771 USA (e-mail: karl.f.huemmrich@ nasa.gov).

J. A. Gamon is with the University of Alberta, Edmonton, AB T6G 2R3, Canada.

C. E. Tweedie is with the University of Texas at El Paso, El Paso, TX 79968 USA.

D. R. Landis is with the Sigma Space Corporation, Lanham, MD 20706 USA E. M. Middleton is with the National Aeronautics and Space Administration (NASA), Greenbelt, MD 20771-0001 USA.

Color versions of one or more of the figures in this paper are available online at http://ieeexplore.ieee.org.

Digital Object Identifier 10.1109/JSTARS.2013.2253446
Index Terms-Environmental factors, ecosystems, geoscience and remote sensing, hyperspectral imaging, remote sensing, vegetation mapping.

\section{INTRODUCTION}

$\mathbf{H}$ IGH northern latitudes are undergoing dramatic changes in climate. Warming trends have been observed in northern regions and Global Circulation Model predictions indicate arctic and boreal regions are likely to warm by several degrees over the next century, a greater rate than other regions on the globe [1], [2]. In high latitudes seasonal shifts in surface properties involve freezing and thawing of water, so relatively small temperature changes around the freezing point can result in significant environmental shifts. Along with temperature changes, significant changes in precipitation and evapotranspiration are also predicted for these regions [1], [2].

Tundra vegetation is expected to be particularly responsive to climate change. Increased warming during the growing season is likely to alter production by lengthening the growing season and increasing metabolic activity [3]-[5]. Changes in seasonal air temperature may increase soil temperatures and the active layer depth to permafrost. This, in turn, affects soil microbial activity, nutrient cycles and soil moisture [6], [7], which alter existing plant growth and competitive species interactions resulting in dramatic changes in vegetation composition. Further, tundra ecosystems are often moisture limited, so climate induced changes in precipitation patterns and surface hydrology will also act to alter vegetation growth patterns [8], [9].

A unique characteristic of the tundra ecosystem is the relative dominance of non-vascular plants in the landscape, such as mosses and lichens. In some cases, mosses dominate local habitats in the tundra because of their tolerance to extreme cold, dessication, water-logging, and low light [10]. Lichens can survive extreme climate conditions such as drought and persistent freezing as well [11]-[13]. Tundra warming manipulation experiments have shown a decline in lichens with an increase in vascular plants suggesting changing proportions of tundra plant types as climate changes [14].

Non-vascular plants can provide a significant fraction of tundra carbon uptake and should be explicitly included in descriptions of tundra carbon fluxes. Photosynthesis of tundra vascular plant canopies has been described with strong relationships found between leaf area or the fraction of absorbed photosynthetically active radiation and gross primary productivity [15], [16], [3]. However, the net primary productivity 
(NPP) of mosses have been shown to represent about 25-30\% of total above-ground NPP in several tundra sites including; tussock tundra [9], coastal tundra [17] and tundra heath [18]. In other cases mosses were found to dominate tundra photosynthetic $\mathrm{CO}_{2}$ fluxes [19], [20].

There are further important physiological differences between vascular and non-vascular plants that affect tundra water and energy balance. Mosses and lichens do not have roots, so cannot access soil moisture below the surface. Instead they depend on water from atmospheric humidity, ground water, or precipitation. They also do not possess stomata and therefore lose water readily to the atmosphere and many species are adapted to survive long periods of desiccation. [21]. They may also act as an insulating layer to heat transport between the soil and the atmosphere [22]. Thus, in areas where these non-vascular plants make up a significant portion of the vegetation cover the response of ecosystem carbon and energy balance to environmental changes is expected to differ from that of vascular plant-dominated vegetation and must be accounted for in tundra ecosystem modeling.

The difficulties in working in remote tundra locations have always incurred large logistical costs, therefore observations of ecosystem change using remote sensing provide an expedient and economical method of collecting repeatable and consistent measurements over large areas. Importantly, most remote sensing theory of vegetation has been derived from studies focused on temperate crops and forests and thus the interpretation of conventional remote sensing tools is often ambiguous for northern landscapes. There are several unique features of the tundra that affect the interpretation of remotely sensed data [23]. Non-vascular plants can represent significant fractions of the tundra landscape cover, and these non-vascular plants have different spectral characteristics as well as different physiological responses from vascular plants or from bare soils [24]-[26]. For example, remote sensing studies have been able to detect changes in lichen-dominated areas due to responses to both short-term temperature anomalies as well as long-term temperature trends [27], [28].

This study investigates the importance of non-vascular plants in the tundra landscape and examines their effects on tundra carbon uptake, using spectral reflectance to distinguish these different functional types. We explore the concept of "optical types" [29] to scale from ground-based in situ measurements to landscapes using satellite observations to examine vegetation functional type patterns across the tundra.

\section{MATERIALSAND METHODS}

\section{A. Study Area}

The study examines an area mainly located north and west of the town of Barrow, AK, including most of the Barrow Environmental Observatory. Specific study plots are located at $71^{\circ}$ 19 ' 19.1" N $156^{\circ} 36$ ' 15.9" W, approximately seven kilometers east of Barrow. The area is classified as moist acidic coastal tundra [30]. Barrow has a mean annual temperature of $-12.0^{\circ} \mathrm{C}$, with a minimum mean monthly temperature of $-26.6^{\circ} \mathrm{C}$ in February and maximum mean monthly temperature of $4.7^{\circ} \mathrm{C}$ in July. More than half of the $106 \mathrm{~mm}$ of annual precipitation falls as rain during a 3-month period from July through September, with the ground being snow covered from September through May to mid-June [31].

The tundra community at Barrow, AK consists of an overstory dominated by vascular plants (mostly graminoids) and an underlying mat of mosses [32]. Vascular plants at Barrow include dwarf shrubs, forbs, and perennial herbs but the most dominant growth form is graminoid [30]. Common vascular species are: Carex aquatilis, Dupontia fischerii, Eriophorum angustifolium, E. scheuzerii, Luzula confusa, Petasites frigidus, Potentilla hyparctica, and Salix rotundifolia. Mosses are a significant portion of the community and in some areas may account for more biomass than vascular plants [33]. Moss species include: Dicranum elongatum, D. undulatum, Drepanocladus revolvens, Polytrichum (juniperum), and Sphagnum spp. Lichens are scattered throughout the drier areas but are not as abundant or productive as mosses and graminoids [34] and include the species: Alectoria nigricans, Cetraria cucullata, $C$. nivalis, and Dactylina arctica.

\section{B. Measurements}

This project included: 1) the collection of in situ measurements of plots for the three vegetation functional types, including photosynthesis and spectral reflectance; 2) measurements of ground cover amount and spectral reflectance at every meter along a $100 \mathrm{~m}$ transect; 3) development of relationships between spectral reflectance and both photosynthesis and cover amount; 4) estimation of LUE across a tundra transect; and 5) application of these findings to the spectral information collected from Hyperion.

Vegetation measurements were designed to relate photosynthetic rate to spectral reflectance. Tundra vegetation were grouped into three functional groups; vascular plants, mosses, and lichens, with at least four replicates per group measured on any one day. Each replicate provided a different species from each group in an attempt to measure the variability within a group. Field sampling for this study was conducted on July 20 and August 5, 2001, near the peak of the growing season in this area.

Spectral reflectance measurements were collected at 51 plots, each about $15 \mathrm{~cm}$ in diameter, representing nearly pure areas of representative tundra species. Photosynthetic gas exchange measurements were collected at 17 of the plots. All of the study plots were in very close proximity $(<15 \mathrm{~m})$ to a $100 \mathrm{~m}$ linear transect that was also optically sampled at frequent intervals throughout the summer [35].

$\mathrm{CO}_{2}$ gas exchange was measured at 17 plots where a $14.6 \mathrm{~cm}$ diameter collar of acrylic plastic was embedded in the ground. When measurements were made, the plot was enclosed in a clear acrylic chamber constructed of $0.3175 \mathrm{~cm}$ thick acrylic tube glued to a $0.635 \mathrm{~cm}$ thick acrylic top and a closed gas exchange system was connected to the chamber (LI-6200, LiCOR, Lincoln, NE). Each individual plot was measured under ambient environmental conditions for net photosynthesis and then the measurement was repeated with the chamber covered with a black cloth to block out light to provide an estimate of dark respiration. Gross photosynthesis was calculated as the difference between the net photosynthesis, measured with the clear chamber, 
and dark respiration, measured with the chamber covered. A quantum sensor mounted on the chamber top measured incident photosynthetically active radiation (PAR). The chamber had a PAR transmittance of 95\% [36]. Photosynthetic light-response curves were developed using household window screen material as neutral density filters to control incident PAR, allowing photosynthesis measurements for each functional type to be rapidly collected under a range of light levels.

Light use efficiency (LUE) was determined as the ratio of absorbed light and gross photosynthesis:

$$
\varepsilon=\frac{G}{f_{\mathrm{PAR}} Q_{i}}
$$

where $\varepsilon$ is LUE, G is gross photosynthesis with units of $\mu \mathrm{mol} \mathrm{CO}_{2} \mathrm{~m}^{-2} \mathrm{~s}^{-1}, \mathrm{Qi}$ is incident PAR with units of $\mu \mathrm{mol}$ photons $\mathrm{m}^{-2} \mathrm{~s}^{-1}$ (i.e., photosynthetic photon flux density, or PPFD) and $f_{\text {PAR }}$ is the fraction of the PAR absorbed by the vegetation (unitless). Absorbed PAR (APAR) is the product of $f_{\mathrm{PAR}}$ and incident PAR.

$f_{\text {PAR }}$ is not well defined and difficult to determine for vegetation with low growth forms such as lichens and mosses. We assumed that no PAR was transmitted through moss and lichen mats, so for these vegetation types $f_{\mathrm{PAR}}$ is 1-PAR albedo. PAR albedo is estimated by integrating the measured spectral reflectance (see below) between 400 and $700 \mathrm{~nm}$. For the vascular plant plots $f_{\text {PAR }}$ is determined using the linear relationship between Normalized Difference Vegetation Index (NDVI) and $f_{\text {PAR }}$ described in Huemmrich et al. [36].

The optical field sampling consisted of measurements of the small single species plots, as well as measurements collected at every meter along a $100 \mathrm{~m}$ transect to observe areas of mixed coverage [35], [37], [38]. Optical measurements were collected using two portable field spectrometers (UniSpec, PP Systems, Haverhill, MA). These spectrometers measured reflectance between 310 and $1130 \mathrm{~nm}$ sampling at approximately $3 \mathrm{~nm}$ intervals.

For plot measurements, the spectrometer was fitted with a glass fiber optic cable connected to a stainless steel ferrule, which provided a $20^{\circ}$ field of view. Reflected irradiance measurements were collected with the end of the fiber optic cable held vertically between 30 and $40 \mathrm{~cm}$ above the surface to view an area of less than $15 \mathrm{~cm}$ diameter to match the area of gas exchange measurements. Within seconds of collecting a surface measurement, a reference measurement was made of a calibration panel (Spectralon, Labsphere, Inc. North Sutton, NH). The speed of this procedure allowed the acquisition of data even under cloudy conditions. Three reflectance spectra were collected for each sampled plot, and were averaged to produce one spectrum per plot. In addition to the vegetation plots, spectral measurements for nongreen materials including bare soil, open water, and areas of standing dead vascular plants, were collected soon after snowmelt and before the start of green-up. For the vegetation plots, ground-based spectral reflectance measurements were collected near the height of peak productivity period in early August (August 5 and 8, 2001) and reflectance for nongreen plots were collected throughout the summer (June 20 and 30, July 15, August 8 and 22, and September 3, 2001).
To characterize spectral reflectance patterns at multiple spatial scales, spectral measurements were made at $1 \mathrm{~m}$ intervals along a $100 \mathrm{~m}$ linear track system [35], [38]. The track was supported less than a meter above the tundra surface by tripods with a tram cart riding on the track carrying a dual channel spectroradiometer (Unispec DC, PP Systems). From the spectrometer were two fiber-optic cables mounted on a mast and boom attached to the cart, one attached to a diffuser head viewing upward, the other on the boom pointing vertically downward to view an area south of the track with a field-of-view of approximately $1 \mathrm{~m}$ in diameter. With each measurement of reflected radiance, a measurement of incident irradiance was also acquired at the same time for a determination of surface reflectance. Due to the coincident measurements of both incoming and reflected radiation this system was able to correct for effects of varying cloud cover. The tram system collected spectral measurements that were repeatable throughout the growing season while minimizing disturbance to the tundra surface [35], [38]. In this study we used measurements from the peak of the growing season period collected on August 10, 2001.

Processing the ground-measured spectral reflectance data included interpolating the spectral bands to $1 \mathrm{~nm}$ intervals. Due to instrument noise at the ends of the spectrometer range, the usable spectral range was between 400 and $1000 \mathrm{~nm}$. The processing used freely available software (Multispec v.4.0, http:// specnet.info/specnet_toolkit.htm). The spectral reflectance data were then convolved to match the approximately $11 \mathrm{~nm}$ band passes of the Hyperion instrument [39] in subsequent analyses.

Imaging spectrometer data were acquired on July 20, 2009 (day 201) by the Hyperion instrument on the Earth Observing-1. Hyperion provides data in 220 spectral bands from 0.4 to $2.5 \mu \mathrm{m}$ at 30-meter resolution and a $7.5 \mathrm{~km}$ wide swath [39]. The satellite data were atmospherically corrected to surface reflectance using the Atmosphere Removal algorithm (ATREM) [40], [41]. To match the spectral range of the ground-based spectral data only 55 of the continuous Hyperion bands between 437 and 993 nm were used.

Discriminant analysis was used to separate the functional groups based on optical properties, determining the important spectral bands and simplifying the number of independent variables [42]. The plot data were divided into four groups: vascular plants, mosses, lichens, and nongreen materials (bare soil, dead vegetation, and standing water). Inputs to the discriminant analysis using Systat (Version 13, Systat Software, Inc., Chicago, IL) were plot reflectance spectra convolved to the Hyperion bands. The analysis used a forward stepwise method (Wilks' Lamda) to test for significant mean group differences, using a probability of $\mathrm{F} \leq 0.05$ to include bands and $\mathrm{F} \geq 0.10$ to remove the band.

At each meter along the $100 \mathrm{~m}$ transect a visual estimate of species abundance was made over the period August 8-11, 2001 using a $1 \mathrm{~m}$ by $1 \mathrm{~m}$ quadrat. The species data were converted into percent area of each of the vegetation functional types and nongreen material types. We estimate errors in the estimation of coverage to be $\pm 15 \%$ cover. Because of the three dimensional structure of the vegetation the sum of the coverage was more than $100 \%$. For this analysis, the total measured cover values 
were normalized so total cover equals $100 \%$ as is generally done in linear unmixing approaches.

LUE was determined for areas with mixtures of different functional types as the weighted sum of the LUE from the pure plots, where the weight coefficients were the normalized fractional cover values. This calculation assumes that the incident PAR is absorbed by the landscape components proportional to their normalized cover fraction and was applied to determine LUE for both the transect data and the Hyperion satellite imagery.

Chlorophyll concentrations are a key physiological factor related to maximum photosynthetic rates. We estimated chlorophyll concentrations using Gitelson's three-band model:

$$
C_{i}=\left(\frac{1}{\rho_{\lambda 1}}-\frac{1}{\rho_{\lambda 2}}\right) \rho_{\lambda 3}
$$

where the spectral index $\mathrm{C}_{i}$ is proportional to the chlorophyll concentration, and $\rho_{\lambda}$ is the reflectance for a given wavelength band, $\lambda$. Wavelengths chosen are maximally sensitive to absorption by chlorophyll and other pigments $(\lambda 1=549 \mathrm{~nm})$, are influenced primarily by non-chlorophyll pigments $(\lambda 2=$ $793 \mathrm{~nm})$, and where reflectance is controlled by leaf scattering $(\lambda 3=793 \mathrm{~nm})[43]-[45]$.

The cover estimates of the functional types retrieved from the Hyperion imagery were used to derive landscape LUE patterns. The LUE per pixel was calculated as described above and compared with chlorophyll concentration estimates obtained using (2).

\section{RESULTS}

The physiological measurements identify differences relating to photosynthetic carbon exchange among the three vegetation functional types. From the plot gas exchange data, LUE for each functional type was calculated as the slope of a linear regression between gross photosynthesis and APAR, forced through the origin (Fig. 1, Table I). Lichens, mosses, and vascular plants all had different LUE values. Vascular plants had significantly higher net photosynthetic rates and LUE than the other two functional types. The vascular plant LUE from this study $\left(0.0134 \mathrm{~mol} \mathrm{C} \mathrm{mol}^{-1}\right.$ quanta) was close to that previously determined for a vascular plant overstory near Barrow (LUE $=0.0126 \mathrm{~mol} \mathrm{C} \mathrm{mol}^{-1}$ quanta [36]) and within the $95 \%$ confidence interval of the slope from the regression in this study (i.e., the vascular plant LUE). This was noteworthy as the LUE in this study was based only on measurements collected during the middle of the growing season, while the Huemmrich et al. [36] LUE was derived from measurements collected throughout the growing season, suggesting the LUE for vascular plants was relatively stable over much of the season, as well as having similar LUE values for vascular plants in mixtures with mosses or growing alone.

The LUE for mosses and lichens were much lower than for vascular plants. There was a significant difference, however, between these two functional types (Table I) with mosses having a LUE almost 50\% greater than lichens (a similar analysis for LUE of the moss data was presented in [36]).

The in situ spectral reflectance measurements of the plots were divided up into four groups: vascular plants $(\mathrm{n}=22)$,

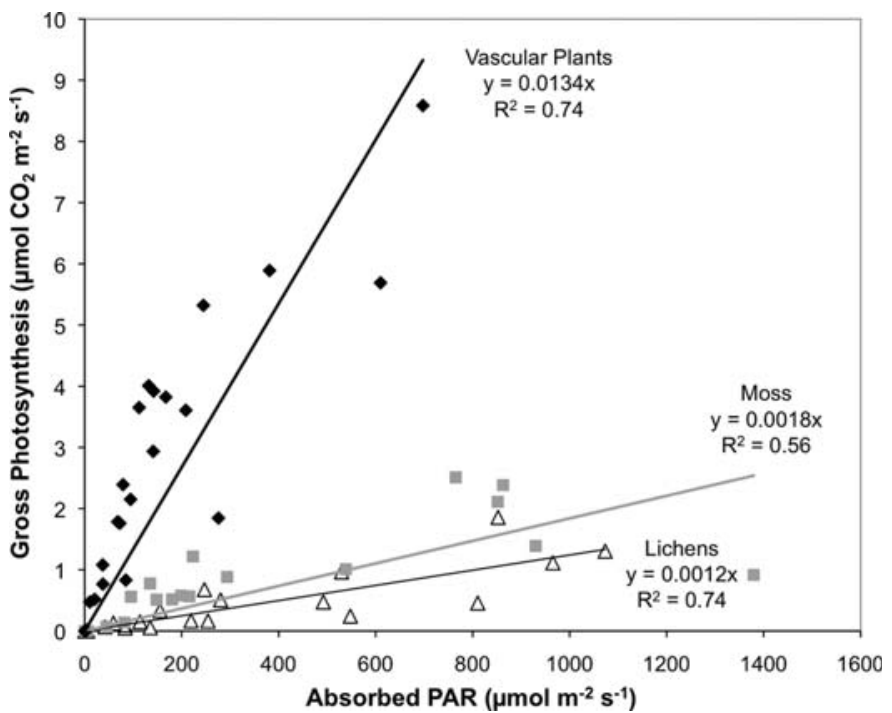

Fig. 1. Absorbed PAR and gross photosynthesis for the three vegetation functional types from plot data collected July 20 and August 5, 2001. Light use efficiency for each functional type was calculated from these data as the slope forced through the origin. See Table I for description of regressions.

TABLE I

Light Use EFFICIENCY BASEd ON REgRessions BetweEn NeT Photosynthesis AND APAR From Plot DATA. LUE IS IN UNITS OF mol C $\mathrm{mol}^{-1}$ ABSORBED QUANTA

\begin{tabular}{|c|r|r|r|}
\hline & \multicolumn{1}{|l|}{$\begin{array}{l}\text { Vascular } \\
\text { Plants }\end{array}$} & \multicolumn{1}{l|}{ Moss } & \multicolumn{1}{l|}{ Lichen } \\
\hline LUE & 0.01337 & 0.00184 & 0.00124 \\
\hline $\begin{array}{c}\text { St. Err. of } \\
\text { Slope }\end{array}$ & 0.00101 & 0.00022 & 0.00011 \\
\hline Num. Obs. & 29 & 25 & 28 \\
\hline $\mathrm{R}^{2}$ & 0.74 & 0.56 & 0.74 \\
\hline $\mathrm{P}$ & $<0.01$ & $<0.01$ & $<0.01$ \\
\hline
\end{tabular}

mosses $(\mathrm{n}=11)$, lichens $(\mathrm{n}=18)$, and nongreen material $(\mathrm{n}=19)$ (Fig. 2). Generally, the vascular plant and moss spectra were similar, and display typical green plant spectral reflectance patterns, including more variation in the near infrared than in visible wavelengths. In comparison, lichen spectra had much higher visible reflectance and were more variable in all wavelengths. Spectral patterns for the nongreen materials were clearly different for dead vegetation, bare soil, and water. Generally the spectral variability for the entire nongreen group increases as a function of wavelength.

Discriminate analysis provided an objective tool to evaluate the ability of optical sampling to distinguish functional groups and to identify a subset of the spectral bands to do this separation. The stepwise method for discriminate analysis reduced the number of wavebands from 55 to five, yet retained separation of functional types. The five chosen bands were located in key locations of typical green plant spectra (Fig. 2); at the blue (488 $\mathrm{nm})$ and red $(671 \mathrm{~nm})$ chlorophyll absorption wells, near the inflection point of the red edge $(712 \mathrm{~nm})$, at the shoulder of the red edge $(763 \mathrm{~nm})$, and in the near infrared "plateau" $(834 \mathrm{~nm})$. Mulhern [46] identified the blue band as an important spectral region for separating lichens from soils. The discriminate analysis functions (Fig. 3) correctly predicted $83 \%$ of group membership overall, with $86 \%$ correct for vascular plants, $91 \%$ for 


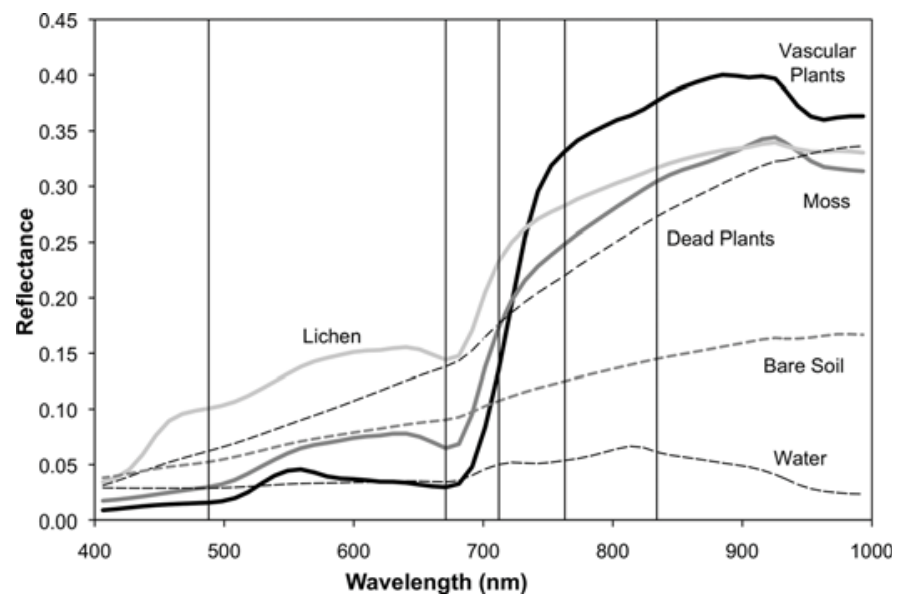

Fig. 2. Endmember spectral reflectance for each cover type, vertical lines indicate wavelengths used in the discriminant analysis.

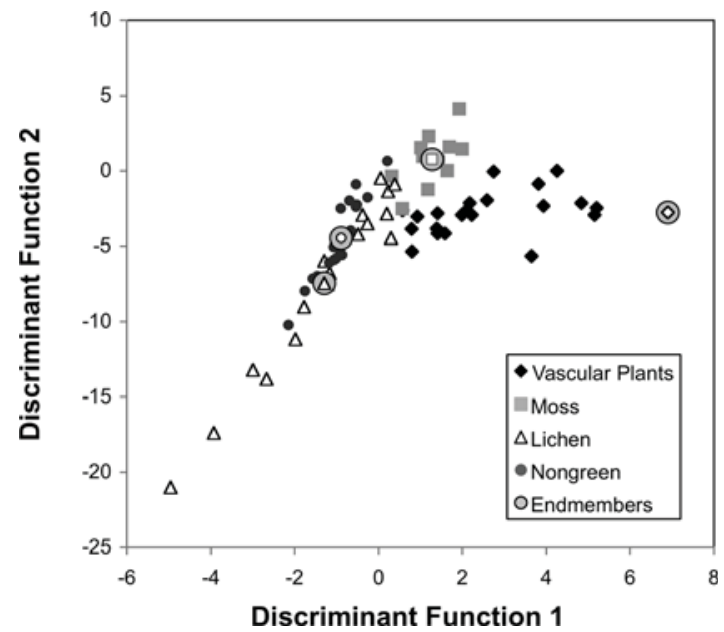

Fig. 3. The distribution of data from plots using the first two functions derived from discriminate analysis for the three vegetation functional types and nongreen materials. The larger gray circles indicate values used as endmembers in the unmixing analysis. For the endmember points the symbol within the circle indicates the vegetation functional type of that endmember.

mosses, $95 \%$ for the nongreen materials, and $61 \%$ for lichens. Lichen errors were mainly due to confusion with the nongreen materials (Fig. 3).

Even at the scale of one square meter, the cover estimates along the tram transect show that all square meter plots consisted of mixtures of multiple cover types (Fig. 4). The observed cover estimates included little bare ground with maximum coverage of $20 \%$, while standing dead vegetation ranged from $0-70 \%$, and water from $0-100 \%$. Moss coverage ranged from $0-100 \%$, but when normalized to a $100 \%$ maximum total coverage maximum moss coverage was $40 \% \pm 7 \%$, based on the propagation of an assumed $15 \%$ error in the original observations. Lichen coverage ranged from $0-90 \%$ with $35 \% \pm 7 \%$ maximum normalized lichen coverage. Vascular plant coverage ranged between $40-150 \%$, with normalized coverage of $18-88 \% \pm 9 \%$. Vascular plant coverage was highest in the locally low areas, particularly the areas with standing water, while moss coverage was highest in locally low areas without standing water and on the edges of the wet areas. Lichen coverage was highest in the locally high areas where bare soil patches also occurred. These spatial patterns indicate the role of microtopography on the distribution of the functional types.

The transect coverage observations indicate how heterogeneous the tundra is, as areas over a few square centimeters in size generally consist of mixtures of multiple types. Therefore, to estimate LUE at that scale of a $30 \mathrm{~m}$ Hyperion pixel, the fractions of each functional type must be determined. We used the optical measurements to scale from plot-level LUE to $30 \mathrm{~m}$ areas. Since the discriminant functions optimized separation of the different functional types with a small number of spectral bands, we used the distance to endmembers in the discriminate analysis function space to estimate cover fractions in mixed pixels. Assuming that the range of in situ plot reflectances provide a reasonable description of the variability of plot type, the endmembers for the moss, lichen, and nongreen cover types were assigned values of the average of the plot reflectances. However, variability in the vascular plants reflectance is driven by differences in green leaf area index. To account for that variability the vascular plant endmember was chosen to be the "greenest" plot spectra (i.e., spectra with the highest NDVI, which was also the greatest distance from the average of all the plot values in the discriminate analysis function space).

Endmember reflectance for each functional type and reflectances at each meter along the transect were transformed using the discriminate analysis functions. The distances in the discriminate analysis space between the coverage estimates for each square meter and the endmembers were calculated, these were related to the observed coverage to create transfer functions. The statistical associations between distance from endmembers and observed coverage were low due to large observation errors relative to the range of values, with $R^{2}$ values of $0.39,0.13$, and 0.19 for vascular plants, mosses, and lichens, respectively (Table II). Nevertheless, the cover fractions determined from the in situ reflectance were found to be in close agreement with sampled cover fractions (Fig. 6), with root mean square error (RMSE) of $11 \%$ cover for vascular plants, $8 \%$ for moss, $9 \%$ for lichen, and an overall RMSE of $9 \%$ cover.

LUE was calculated for each square meter block along the transect using the observed cover fraction and coverage estimated from the reflectance spectra (Figs. 5 and 7). Along the 


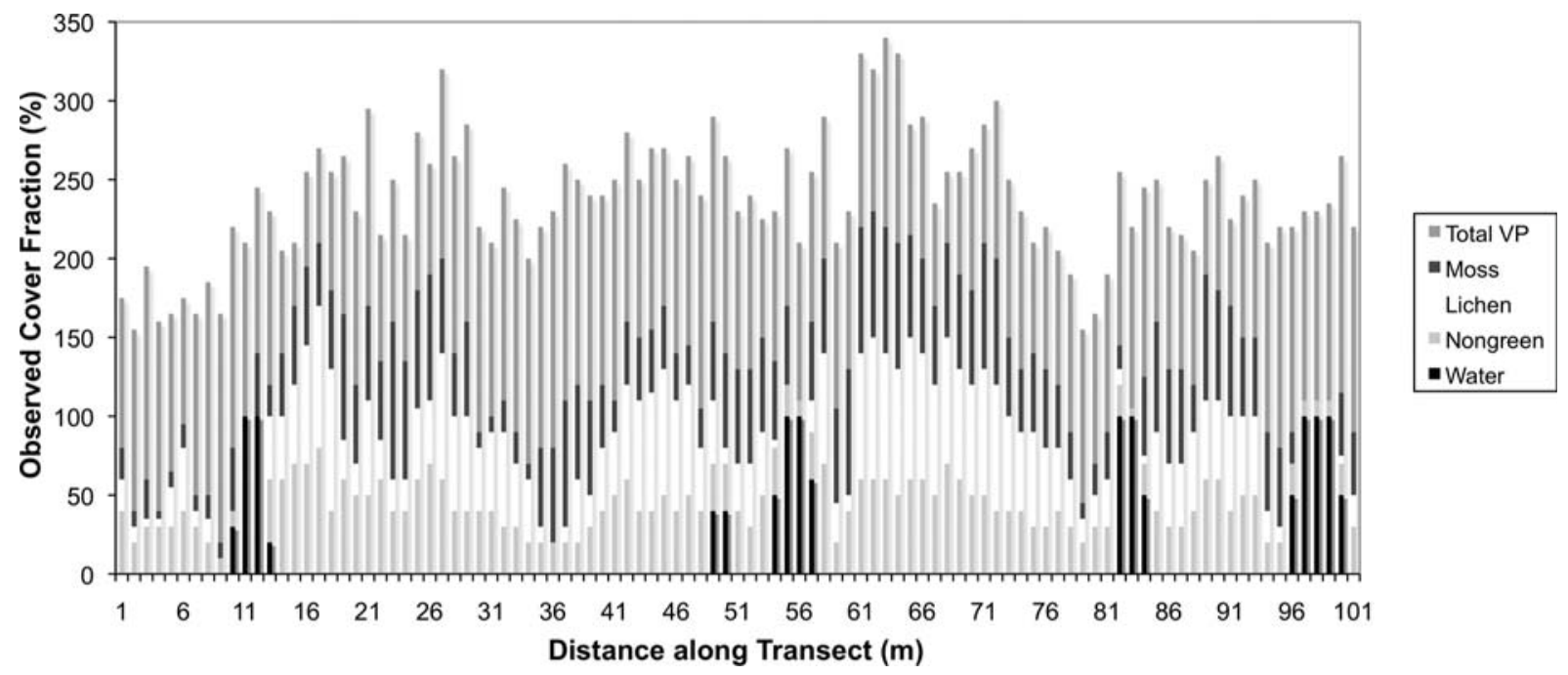

Fig. 4. Observed functional type coverage at $1 \mathrm{~m}$ intervals along the transect, visually estimated over the period August 8-11, 2001. Because the vegetation is 3-dimentional, total cover fractions were over $100 \%$. In the data analysis the total cover fractions were normalized to equal $100 \%$.

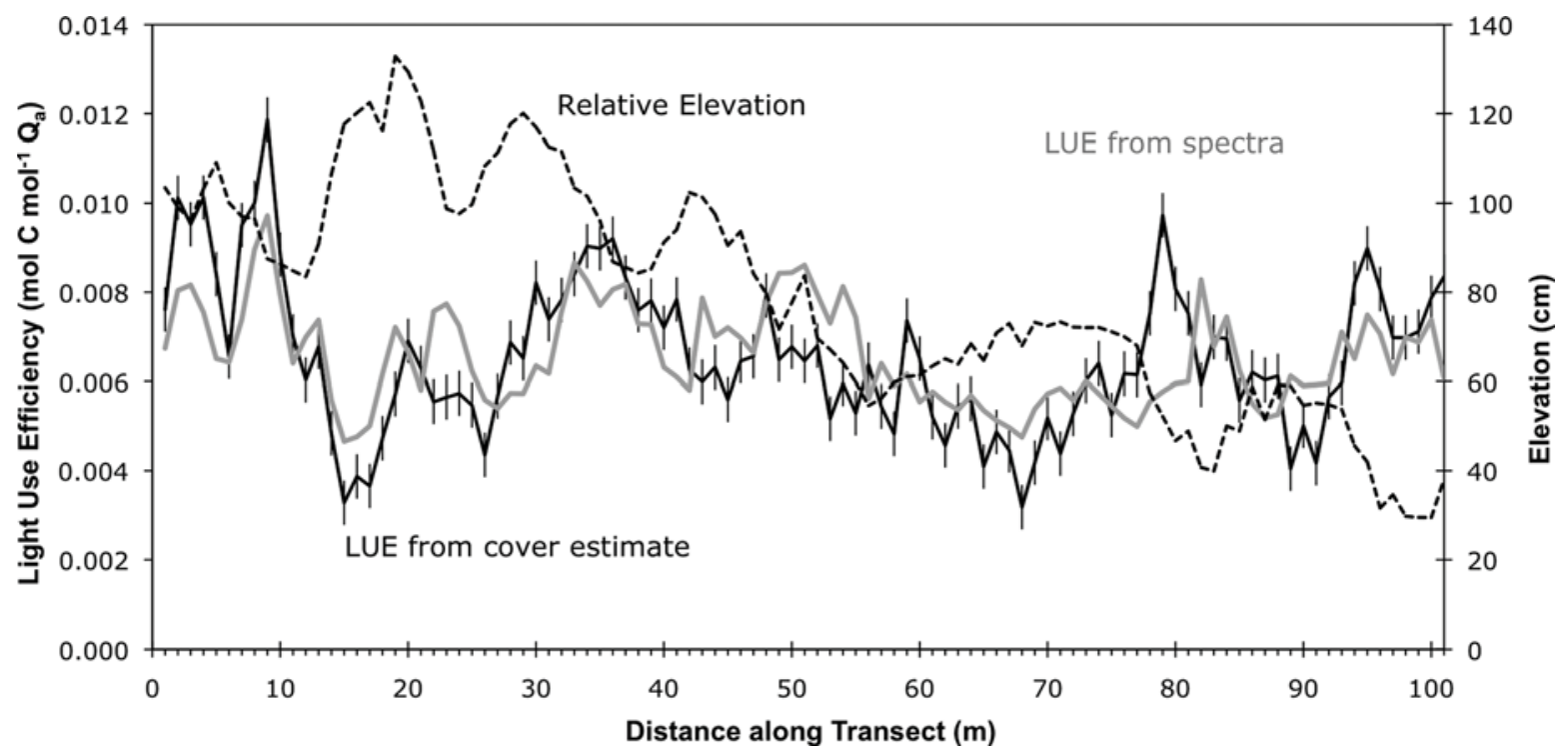

Fig. 5. LUE along the $100 \mathrm{~m}$ transect shown with the black line was estimated from the functional type coverage (shown in Fig. 4) and light use efficiency (shown in Fig. 1), along with LUE estimated using coverage derived from spectral unmixing shown with the gray line. Microtopography is shown as dashed line. Error in Observed LUE estimate is $0.00136 \mathrm{~mol} \mathrm{C} \mathrm{mol}{ }^{-1}$ quanta, RMSE in LUE derived from observations compared to LUE from spectra is $0.00266 \mathrm{~mol} \mathrm{C}$ mol $^{-1}$ quanta.

TABLE II

DESCRIPTION OF RELATIONSHIPS IN SPECTRAL SPACE BETWEEN THE Statistical Distance to ENDMEMBERS AND COVERAGE ESTIMATE Observations, ACQuired Along the Tram Transect. The Errors are Expressed in Percent Coverage. For all Cases the Number of OBSERVATIONS IS 100

\begin{tabular}{|c|r|r|r|}
\hline & \multicolumn{1}{|c|}{$\begin{array}{c}\text { Vascular } \\
\text { Plants }\end{array}$} & Moss & \multicolumn{1}{c|}{ Lichen } \\
\hline $\mathrm{R}^{2}$ & 0.39 & 0.13 & 0.19 \\
\hline $\mathrm{P}$ & $<0.01$ & $<0.01$ & $<0.01$ \\
\hline Est. Obs. Error & 9.5 & 7.1 & 7.0 \\
\hline SE of Regression & 10.8 & 8.4 & 9.0 \\
\hline
\end{tabular}

transect LUE was quite variable, with maximum and minimum values occurring within $6 \mathrm{~m}$ of each other (Fig. 7). Variability in LUE was affected by microtopography, with higher values of
LUE tending to occur in locally low, wet areas. This variability over the $100 \mathrm{~m}$ distance produced a fourfold difference in LUE with values from 0.003 to $0.012 \mathrm{~mol} \mathrm{C} \mathrm{mol}^{-1}$ quanta for the in situ observations. The average errors for estimating LUE were similar for the two methods: $0.0014 \mathrm{~mol} \mathrm{C} \mathrm{mol}{ }^{-1}$ quanta for the method using observed coverage and $0.0015 \mathrm{~mol} \mathrm{C} \mathrm{mol}^{-1}$ quanta for the LUE based on the remote sensing approach. The two different LUE calculations have a correlation of 0.62 with a RMSE of $0.0013 \mathrm{~mol} \mathrm{C} \mathrm{mol}^{-1}$ quanta.

The equations relating spectral reflectance and functional type coverage derived from the transect data were the applied to the Hyperion imagery to create a continuous fields description of the coverage of the functional types for the tundra around Barrow (Fig. 8(b)). Over this area the distribution of vascular plant coverage per pixel had a maximum value of $74 \%$ with a distribution peak of $32 \%$, for mosses the maximum coverage 


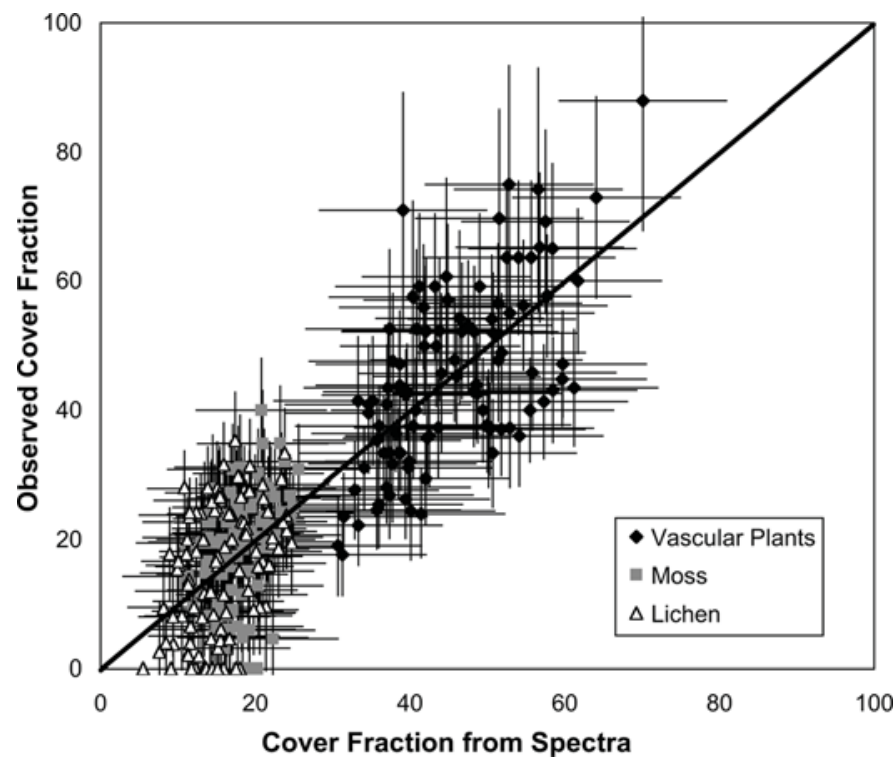

Fig. 6. Comparison between observed vegetation functional type coverage normalized to $100 \%$ for vascular plants, mosses, and lichens along the transect and cover fractions estimated from spectral reflectance. Line is 1 to 1 line. The absolute error in visual estimates is approximately 9\%. The RMSE of spectral retrievals is $9 \%$ absolute.

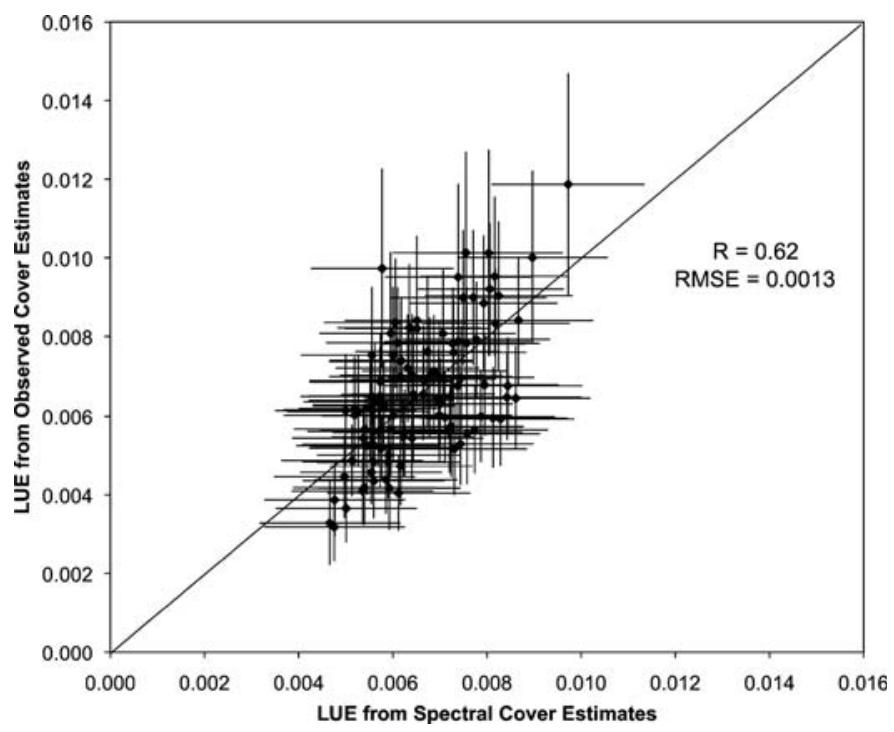

Fig. 7. LUE (mol C $\mathrm{mol}^{-1}$ quanta) along the transect estimated based on observed normalized cover fractions and cover fractions obtained from spectral unmixing. Line is 1 to 1 line. Errors in LUE based on observed cover fractions are due to errors in LUE for the pure functional types and an assumed $15 \%$ error of observed raw coverage amounts. Errors in LUE based on spectrally derived cover fractions are due to errors in LUE for pure functional types and the RMSE of the spectral retrieval of cover fractions.

was $31 \%$ with the distribution peak at $22 \%$, and for lichens the maximum coverage was $22 \%$ with a peak of $10 \%$.

Without ground observations of vegetation type coverage, an examination of an area known to be free of vegetation was used to make an error estimate. The old Naval Arctic Research Laboratory runway was chosen as for this test. For runway pixels vascular plant coverage was as high as $9 \%$, moss $14 \%$, and lichen $13 \%$, compared to expected values of zero percent coverage.
These values were close to the RMSE of coverage from the tram analysis comparing the spectral unmixing with ground observations, suggesting the Hyperion unmixing captured the actual functional type distribution near this level of error.

There are clearly observed spatial patterns in the cover fractions in this landscape. High vascular plant coverage occurred on the margins of drained lakes. Higher lichen coverage tended to be found in drier upland regions. This pattern of lichen occurrence was also observed in the transect measurements (Fig. 4). Moss coverage was more widely distributed, although high moss coverage in the middle of the drained lakes may be erroneous due to confusion between mosses and mixtures of water and vascular plants. Field observations confirm that moss often occurs as a low, "background" layer beneath the vascular canopy of wet tundra in this region [36].

The Hyperion functional type coverage estimates were used to calculate landscape patterns of LUE (Fig. 8(c)). For the vegetated parts of the scene, this Hyperion-based LUE ranged from 0.0021-0.0102 mol C mol ${ }^{-1}$ quanta, a fivefold difference between maximum and minimum LUE. The distribution peak of LUE for this area and the overall average were both 0.0048 mol C mol ${ }^{-1}$ quanta.

The Hyperion-based LUE was compared with the chlorophyll spectral index, $\mathrm{Ci}((2))$. Ci was well correlated with LUE over the study area $\left(\mathrm{R}^{2}=0.69, \mathrm{SE}=0.0006 \mathrm{~mol} \mathrm{C} \mathrm{mol}^{-1}\right.$ quanta $)$ (Fig. 9) suggesting vegetation chlorophyll concentration is a key determinant of LUE for this tundra ecosystem. This suggests that a more direct approach for deriving spatial patterns of LUE for tundra from imaging spectrometry would be based on a simple reflectance-based metric of chlorophyll concentration.

\section{Discussion AND CONCLUSIONS}

This study uses the concept of optical types [29] to examine a key characteristic of ecosystem carbon exchange in the tundra. To have usable optical types one must be able to both identify significant functional differences in vegetation types and spectrally identify these different types. Our grouping of tundra vegetation (vascular plants, mosses, and lichens) meets these criteria. Among the different types, the plot measurements showed distinct differences in LUE, a key variable describing photosynthetic carbon uptake and discriminate analysis showed that the types could be separated based on their spectral reflectance. The ability to link LUE to reflectance characteristics provides an approach to scale from the ground measurements to distributions over a landscape. Using an unmixing approach we were able to create continuous fields of key tundra functional types for this area, an improvement over simple classifications. Results from this study demonstrated how, even at a scale of a square meter, variable mixtures of functional types produced significantly different values for LUE. Unmixing using spectral reflectance provides a unique estimate of LUE for each pixel. Remote sensing provides a way to map large areas and make noninvasive repeat measurements to monitor ecosystem change. Remote sensing is a particularly important tool for observing tundra due to the difficulties and expense involved in traveling to and working in this region, rendering direct field sampling over large areas impractical. 


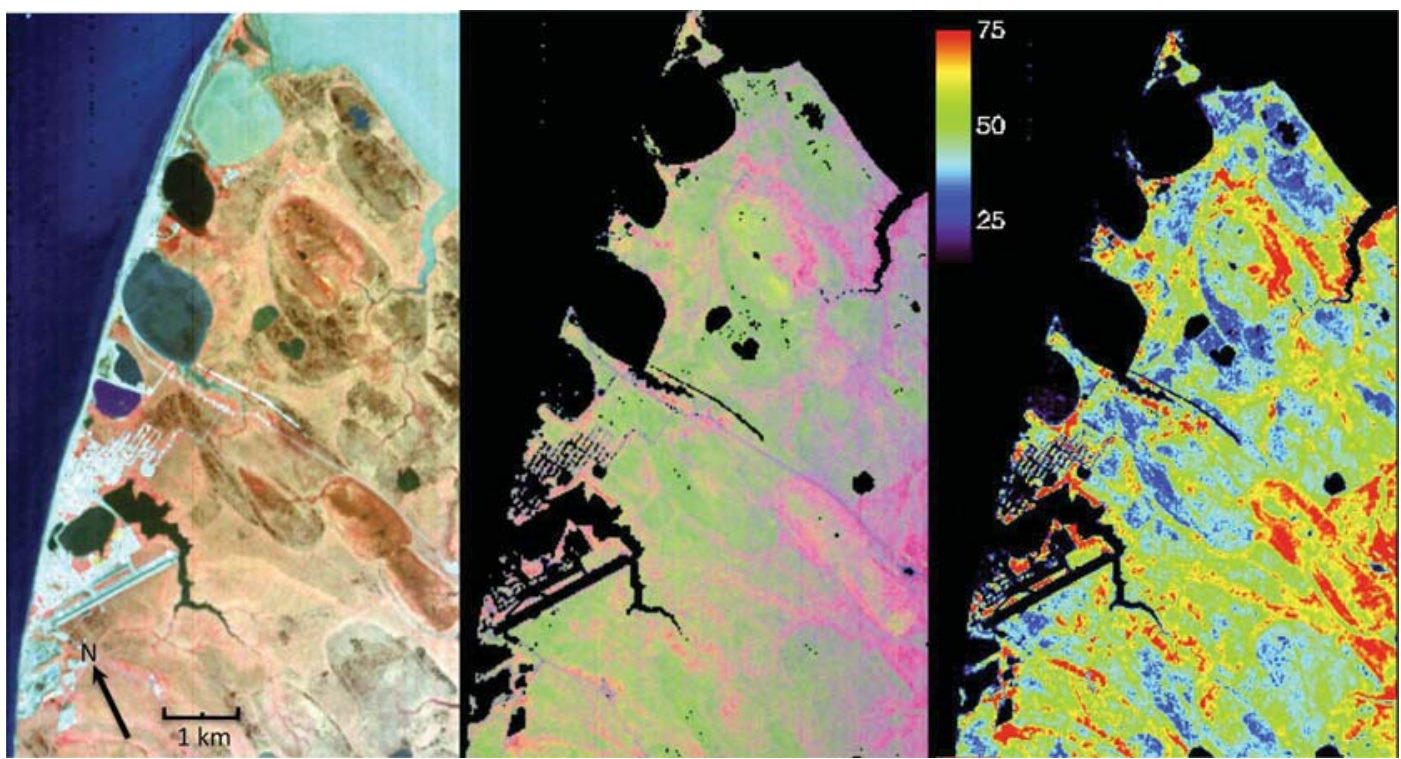

Fig. 8. Three versions of the EO-1 Hyperion image acquired on July 20, 2009 are shown. Left: 3-band (RGB = 834, 671, and 549 nm) composite image of surface reflectance. The grid of light blue lines on the lower left side of the image is the city of Barrow. The straight blue line along the shore near the top of the image is the old airport runway, used in the error evaluation. The oblong features scattered around the region are drained thermokarst lakes and the dark red ones are now marshes. Middle: Three band RGB continuous fields of estimated coverage of vegetation functional types derived from spectral unmixing and scaled between 0 and $50 \%$ coverage. $\mathrm{R}=$ Vascular Plant Cover, $\mathrm{G}=$ Moss Cover, $\mathrm{B}=$ Lichen Cover. Right image: Map of LUE spatial patterns (mol C mol ${ }^{-1}$ quanta $\mathrm{x} 1000)$ based on coverage estimates.

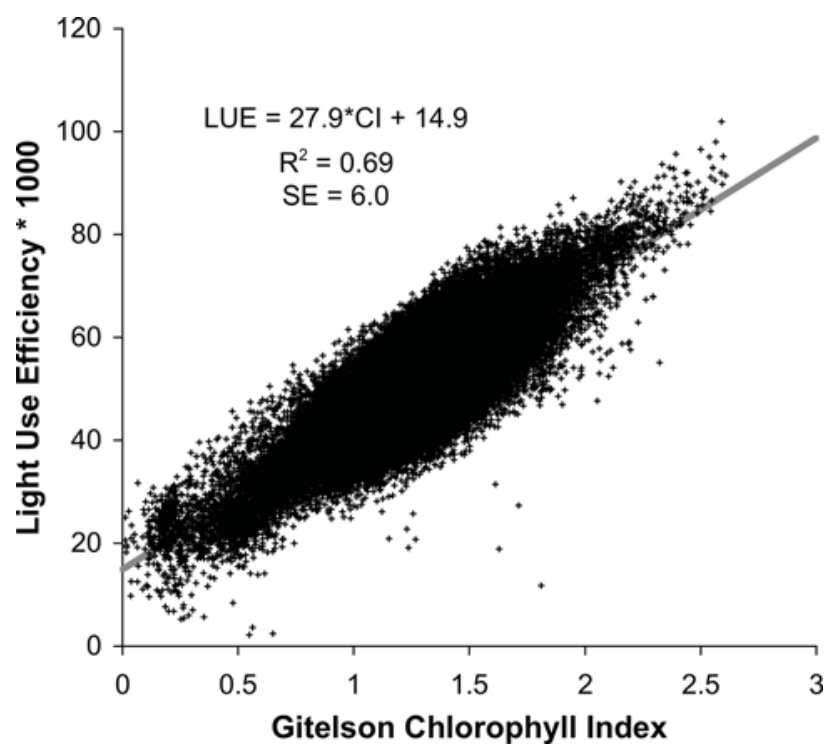

Fig. 9. Scatter plot of chlorophyll index (x-axis) versus LUE (mol C mol-1 quanta $\mathrm{x} 1000)$ based on normalized cover fractions ( $\mathrm{y}$-axis). Both variables were retrieved from the Hyperion image.

The linear unmixing approach used to calculate pixel-level LUE simplifies the tundra canopy as it does not take into account the three dimensional structure of a vascular plant overstory. Vascular plants can grow through mats of mosses and lichens and shade them, decreasing their photosynthetic production [36]. However, vascular plant leaf area index for this region is generally low, with observed midseason values less than 2 [36]. We believe the overall effect of this overstory on the moss and lichen understory production is relatively small in this region due to both the low leaf area combined with generally diffuse light conditions.

This study provided a snap-shot of this landscape at a particular point in time. Seasonal growth of vascular plants will change their relative proportions throughout the growing season and this affects carbon uptake and LUE patterns [38]. Early in the growing season, as vascular plants begin to grow, tundra productivity will be dominated by moss and lichen photosynthesis, with the vascular plant component increasing as the season progresses [36]. Thus, the spatial patterns of coverage and LUE are expected to change through the growing season.

The correlation between LUE calculated from coverage estimates and the chlorophyll index (Ci), even though they use different algorithms and spectral bands, demonstrates how multiple approaches can yield similar results. This convergence is most likely due to plant physiological constraints indicating chlorophyll concentration is a controlling factor in vegetation photosynthetic efficiency, and may provide a more direct approach to deriving LUE.

This study found significant variability in functional type cover fractions, leading to variability in estimated LUE, at local scales (meters) in the field data collected along the transect and at landscape scales $(\mathrm{km})$ in the satellite imagery. The spatial variability shown in LUE estimates is not accounted for in existing carbon flux models. Spatial distributions of vegetation functional types were strongly related to surface microtopography, from which we infer surface hydrology to be a significant controlling factor. These results suggest that climate change affecting surface hydrology [47] will also affect spatial patterns of vegetation distribution and ecosystem carbon exchange. Particularly in a scenario of modified surface hydrology, we can expect that climate change will affect relative coverage due to differing responses of each of the functional types to climate 
change, and that these changes in cover will be associated with altered carbon and energy balance.

Since hydrology is an important factor determining the vegetation functional type coverage, shortwave infrared bands may provide additional information on vegetation water content, improving the retrieval of functional type coverage [48]. This approach was not tested in this study as the field measurements observed only visible and near infrared spectral bands. Recent observations combining NIR and blue bands to detect standing water in coastal tundra [49] may also prove useful at detecting hydrological changes linked to cover type and LUE.

The results of this study are indicative only of this part of the Alaskan coastal tundra and further field studies are required in other parts of the tundra biome to test and extend the results and to evaluate the ability to generalize the results. For example, shrubs are an important component of the tundra biome and shrub coverage has been shown to be increasing in the tundra [50]. Shrubs did not represent a significant cover type in our study area, however, so were not explicitly included in this study. Future work is required to examine shrub optical and physiological characteristics to see if they comprise an optically distinct functional type.

The use of multiple narrow spectral bands for the umixing points to an application for the future NASA Hyperspectral Infrared Imager (HyspIRI) mission for mapping tundra vegetation distribution according to physiological function, hydrology, and microtopography over the entire biome. The concept of optical types (optically distinguishable functional types) may prove to be useful for this kind of functional mapping. Similarly, simple metrics of surface water cover (e.g., [49]) or pigment distribution (e.g., [45]) may provide insight into the proximal causes of functional change in tundra ecosystems.

The close linking of optical properties and carbon flux measurements in this study has provided insights into the functioning of the tundra ecosystem by identifying fine-scale patterns of LUE that may be related to hydrology and microtopography. This study also illustrates new "scaleable" functional mapping techniques that can be extended through the use of satellite remote sensing to larger regions. This approach lends itself to future studies considering how species composition relates to changing ecosystem function and provides a framework for studying ecosystem change through remote sensing that considers shifts in hydrology, species composition, and their effects on carbon balance.

\section{ACKNOWLEDGMENT}

The authors thank S. Houston and E. Anderson for their work on the field data collection. Thanks also go to G. Kinoshita, H. Kwon, R. Zulueta, J. Verfaillie, and B. Hollister for their help and friendship in the field, and the staff of Barrow Arctic Science Consortium (BASC) for logistics support.

\section{REFERENCES}

[1] Impacts of a Warming Arctic: Arctic Climate Impact Assessment (ACIA). Cambridge, U.K.: Cambridge Univ. Press, 2005.
[2] IPCC, Climate Change 2007: The Physical Science Basis. Contribution of Working Group I to the Fourth Assessment Report of the Intergovernmental Panel on Climate Change, S. Solomon, D. Qin, M. Manning, Z. Chen, M. Marquis, K. B. Averyt, M. Tignor, and H. L. Miller, Eds.. Cambridge and New York, U.K. and USA: Cambridge Univ. Press, 2007.

[3] K. F. Huemmrich, G. Kinoshita, J. A. Gamon, S. Houston, H. Kwon, and W. C. Oechel, "Tundra carbon balance under varying temperature and moisture regimes," J. Geophys. Res., vol. 115, no. G00I02, 2010.

[4] E. R. Humpreys and P. M. LaFleur, "Does earlier snowmelt lead to greater $\mathrm{CO}_{2}$ sequestration in two low Arctic tundra ecosystems?," Geophys. Res. Lett., vol. 38, no. L09703, 2011.

[5] M. Jahn, T. Sachs, T. Mansfeldt, and M. Overesch, "Global climate change and its impacts on the terrestrial Arctic carbon cycle with special regards to ecosystem components and the greenhouse-gas balance," J. Plant Nutr. Soil Sci., vol. 173, pp. 627-643, 2010.

[6] M. T. van Wijk, K. E. Clemmensen, G. R. Shaver, M. Williams, T. V. Callaghan, F. S. Chapin, J. H. C. Cornelissen, L. Gough, S. E. Hobbie, S. Jonasson, J. A. Lee, A. Michelsen, M. C. Press, S. J. Richardson, and H. Rueth, "Long-term ecosystem level experiments at Toolik Lake, Alaska, and at Abisko, Northern Sweden: Generalizations and differences in ecosystem and plant type responses to global change," Global Change Biol., vol. 10, no. 1, pp. 105-123, 2004.

[7] E. A. G. Schuur et al., "Vulnerability of permafrost carbon to climate change: Implications for the global carbon cycle," BioScience, vol. 58, no. 8, pp. 701-714, 2008.

[8] L. C. Bliss, J. Svoboda, and D. I. Bliss, "Polar deserts, their plant cover and plant-production in the Canadian High Arctic," Holarctic Ecol., vol. 7, pp. 305-324, 1984.

[9] F. S. Chapin, G. R. Shaver, A. E. Giblin, K. J. Nadelhoffer, and J. A. Laundre, "Responses of Arctic tundra to experimental and observed changes in climate," Ecology, vol. 76, pp. 694-711, 1995.

[10] L. L. Tieszen, P. C. Miller, and W. C. Oechel, "Photosynthesis," in An Arctic Ecosystem: The Coastal Tundra at Barrow, Alaska, J. Brown, P. C. Miller, L. L. Tieszen, and F. L. Bunnell, Eds. Stroudsberg, PA, USA: Dowden, Hutchinson, and Ross, Inc., 1980, pp. 120-139.

[11] L. Kappen, "Response to extreme environments," in The Lichens, V. Ahmadjian and M. E. Hale, Eds. New York, NY, USA: Academic Press, 1974, pp. 311-380.

[12] D. H. S. Richardson, "Photosynthesis and carbohydrate movement," in The Lichens, V. Ahmadjian and M. E. Hale, Eds. New York, NY, USA: Academic Press, 1974, pp. 251-288.

[13] K. A. Kershaw, "Photosynthetic capacity changes in lichens and their potential ecological significance," in Lichen Physiology and Cell Biology, D. H. Brown, Ed. New York, NY, USA: Plenum Press, 1984, pp. 93-109.

[14] J. H. C. Cornelissen, T. V. Callaghan, J. M. Alatalo, A. Michelsen, E. Graglia, and A. E. Hartley, "Global change and Arctic ecosystems: Is lichen decline a function of increases in vascular plant biomass?," $J$. Ecol., vol. 89, pp. 984-994, 2001.

[15] L. E. Street, G. R. Shaver, M. Williams, and M. T. Van Wijk, "What is the relationship between changes in canopy leaf area and changes in photosynthetic $\mathrm{CO}_{2}$ flux in Arctic ecosystems?," J. Ecol., vol. 95, pp. 139-150, 2007.

[16] G. R. Shaver, L. E. Street, E. B. Rastetter, M. T. Van Wijk, and M. Williams, "Functional convergence in regulation of net $\mathrm{CO}_{2}$ flux in heterogeneous tundra landscapes in Alaska and Sweden," J. Ecol., vol. 95, pp. 802-817, 2007.

[17] P. C. Miller, P. J. Webber, W. C. Oechel, and L. L. Tieszen, "Biophysical processes and primary production," in An Arctic Ecosystem: The Coastal Tundra at Barrow, Alaska, J. M. Brown, P. C. Miller, L. L. Tieszen, and F. L. Bunnell, Eds. Stroudsburg, PA, USA: Dowden, Hutchinson and Ross, Inc., 1980, pp. 66-101.

[18] M. Campioli, R. Samson, A. Michelsen, S. Jonasson, R. Baxter, and R. Lemeur, "Nonvascular contribution to ecosystem NPP in a subarctic heath during early and late growing season," Plant Ecol., vol. 202, pp. 41-53, 2009.

[19] J. Douma, M. T. van Wijk, S. I. Lang, and G. R. Shaver, "The contribution of mosses to the carbon and water exchange of arctic ecosystems: Quantification and relationships with system properties," Plant, Cell Environ., vol. 30, pp. 1205-1215, 2007.

[20] L. E. Street, P. C. Stoy, M. Sommerkorn, B. J. Fletcher, V. L. Sloan, T. C. Hill, and M. Williams, "Seasonal bryophyte productivity in the sub-Arctic: A comparison with vascular plants," Functional Ecol., vol. 26, pp. 365-378, 2012. 
[21] M. C. F. Proctor, "The bryophyte paradox: Tolerance of desiccation, evasion of drought," Plant Ecol., vol. 151, pp. 41-49, 2000.

[22] J. Beringer, A. H. Lynch, F. S. Chapin, M. Mack, and G. B. Bonan, "The representation of arctic soils in the land surface model: The importance of mosses," J. Climate, vol. 14, pp. 3324-3335, 2001.

[23] A. Hope and D. Stow, "Shortwave reflectance properties of arctic tundra," in Landscape Function and Disturbance in Arctic Tundra, J. Reynolds and J. Tenhuenen, Eds. Heidelberg, Germany: Springer-Verlag, 1995, vol. 120, Ecological Studies.

[24] W. G. Rees, O. V. Tutubalina, and E. I. Golubeva, "Reflectance spectra of subarctic lichens between 400 and 2400 nm," Remote Sens. Environ., vol. 90, pp. 281-292, 2004.

[25] D. E. Petzold and S. N. Goward, "Reflectance spectra of subarctic lichens," Remote Sens. Environ., vol. 24, pp. 481-492, 1988.

[26] J. E. Vogelmann and D. M. Moss, "Spectral reflectance measurements in the genus Sphagnum," Remote Sens. Environ., vol. 45, pp. 273-279, 1993

[27] I. Olthof and R. Latifovic, "Short-term response of arctic vegetation NDVI to temperature anomalies," Int. J. Remote Sens., vol. 28, pp. 4823-4840, 2007.

[28] I. Olthof and D. Pouliot, "Treeline vegetation composition and change in Canada's western Subarctic from AVHRR and canopy reflectance modeling," Remote Sens. Environ., vol. 114, no. 4, pp. 805-815, 2010.

[29] S. L. Ustin and J. A. Gamon, "Remote sensing of plant functional types," New Phytologist., vol. 186, pp. 795-816, 2010.

[30] J. Brown, K. R. Everett, P. J. Webber, S. F. MacLean, Jr, and D. F. Murray, "The coastal tundra at Barrow," in An Arctic Ecosystem, The Coastal Tundra at Barrow, Alaska, J. Brown, P. C. Miller, L. L. Tieszen, and F. L. Bunnell, Eds. Stroudsberg, PA, USA: Dowden, Hutchison, and Ross, Inc., 1980, pp. 1-29.

[31] K. M. Hinkel, F. E. Nelson, A. E. Klene, and J. H. Bell, "The Urban heat island in winter at Barrow, Alaska," Int. J. Climatol., vol. 23, pp. 1889-1905, 2003.

[32] L. C. Bliss, "The evolution and characteristics of tundra," in Tundra Ecosystems: A Comparative Analysis, L. C. Bliss, O. W. Heal, and J. J. Moore, Eds. Cambridge, U.K.: Cambridge Univ. Press, 1981, pp. 5-46.

[33] P. J. Webber, P. C. Miller, F. S. Chapin, III, and B. H. McCown, "The Vegetation: Pattern and succession," in An Arctic Ecosystem, The Coastal Tundra at Barrow, Alaska, J. Brown, P. C. Miller, L. L. Tieszen, and F. L. Bunnell, Eds. Stroudsberg, PA, USA: Dowden, Hutchison, and Ross, Inc., 1980, pp. 186-218.

[34] F. E. Wielgolaski, L. C. Bliss, J. Svoboda, and G. Doyle, "Primary production of tundra," in Tundra Ecosystems: A Comparative Analysis, L. C. Bliss, O. W. Heal, and J. J. Moore, Eds. Cambridge, U.K.: Cambridge Univ. Press, 1981, pp. 187-225.

[35] D. A. Stow et al., "Remote sensing of vegetation and land-cover change in Arctic tundra ecosystems," Remote Sens. Environ., vol. 89, pp. 281-308, 2004.

[36] K. F. Huemmrich et al., "Remote sensing of tundra gross ecosystem productivity and light use efficiency under varying temperature and moisture conditions," Remote Sens. Environ., vol. 114, no. 3, pp. 481-489, 2010.

[37] J. A. Gamon, Y. Cheng, H. Claudio, L. MacKinney, and D. Sims, "A mobile tram system for systematic sampling ecosystem optical properties," Remote Sens. Environ., vol. 103, pp. 246-254, 2006.

[38] J. A. Gamon, K. F. Huemmrich, R. S. Stone, and C. E. Tweedie, "Spatial and temporal variation in primary productivity (NDVI) of coastal Alaskan tundra: Decreased vegetation growth following earlier snowmelt," Remote Sens. Environ., vol. 129, pp. 144-153, 2013.

[39] S. G. Ungar, J. S. Pearlman, J. A. Mendenhall, and D. Reuter, "Overview of the Earth Observing One (EO-1) mission," IEEE Trans. Geosci. Remote Sens., vol. 41, no. 6, pp. 1149-1159, 2003.

[40] B.-C. Gao, K. B. Heidebrecht, and A. F. H. Goetz, "Derivation of scaled surface reflectances from AVIRIS data," Remote Sens. Environ., vol. 44, pp. 165-178, 1993.

[41] B.-C. Gao, M. J. Montes, C. O. Davis, and A. F. H. Goetz, "Atmospheric correction algorithms for hyperspectral remote sensing data of land and ocean," Remote Sens. Environ., vol. 113, Suppl. 1, pp. S17-S24, 2009.

[42] W. R. Klecka, Discriminant Analysis. Newbury Park, CA, USA: Sage Publications, 1980.
[43] A. A. Gitelson, G. P. Keydan, and M. N. Merzlyak, "Three-band model for non-invasive estimation of chlorophyll, carotenoids, and anthocyanin contents in higher plant leaves," Geophys. Res. Lett., vol. 33, p. L11402, 2006.

[44] S. L. Ustin, A. A. Gitelson, S. Jacquemoud, M. Schaepman, G. P. Asner, J. A. Gamon, and P. Zarco-Tejada, "Retrieval of foliar information about plant pigment systems from high resolution spectroscopy," Remote Sens. Environ., vol. 113, pp. S67-S77, 2009.

[45] A. A. Gitelson, "Nondestructive estimation of foliar pigment (chlorophylls, carotenoids, and anthocyanins) contents: Evaluating a semianalytical three-band model," in Hyperspectral Remote Sens. Vegetation, P. S. Thenkabail, J. G. Lyon, and A. Huete, Eds. New York, NY, USA: Taylor and Francis, 2011.

[46] T. Mulhern, "Spectral Contrasts of Subarctic Vegetation: Basis for Mapping Lichens With Satellite Data," Ph.D. dissertation, University of Maryland, College Park, MD, USA, 1995.

[47] L. C. Smith, Y. Sheng, G. M. MacDonald, and L. D. Hinzman, "Disappearing Arctic lakes," Science, vol. 308, p. 1429, 2005.

[48] C. Roberto, B. Lorenzo, M. Michele, R. Micol, and P. Cinzia, "Optical remote sensing of vegetation water content," in Hyperspectral Remote Sens. Vegetation, P. S. Thenkabail, J. G. Lyon, and A. Huete, Eds. New York, NY, USA: Taylor and Francis, 2011.

[49] S. Goswami, J. A. Gamon, and C. E. Tweedie, "Surface hydrology of an arctic ecosystem: Multi-scale analysis of a flooding and draining experiment using spectral reflectance," J. Geophys. Res., vol. 116, no. G00I07, 2010.

[50] M. Sturm, C. Racine, and K. Tape, "Increasing shrub abundance in the Arctic," Nature, vol. 411, pp. 546-547, 2001.

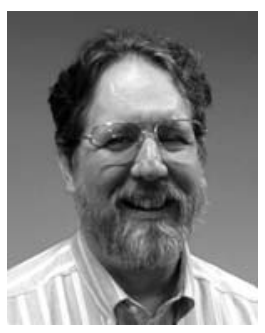

Karl Fred Huemmrich received the B.S. degree in physics from Carnegie-Mellon University, Pittsburgh, PA, USA, and the Ph.D. degree in geography from the University of Maryland, College Park, MD, USA.

$\mathrm{He}$ is currently a Research Associate Professor in the Joint Center for Earth Systems Technology at the University of Maryland Baltimore County. He has developed and used models of light interactions with vegetation, and has studied the use of remotely sensed data to collect information on biophysical variables and land cover type using both computer models and field measurements. His research has involved fieldwork in a variety of habitats including working on operations and data analysis for the Boreal Ecosystem and Atmosphere Study (BOREAS) and the First International Satellite Land Surface Climatology Project Field Experiment (FIFE).

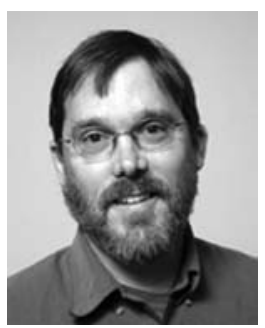

John A. Gamon received the B.S. degree from Yale University, New Haven, CT, USA, in 1979, and the Ph.D. degree from the University of California, Davis, CA, USA, in 1989

Currently, he is a Professor in Earth and Atmospheric Sciences and Biological Sciences at the University of Alberta, Edmonton, Alberta, Canada. His current research involves remote sensing of vegetation function, physiology, and biodiversity.

Craig E. Tweedie was born and raised in Brisbane, Australia, and received all of his university level training at The University of Queensland, graduating with B.Sc., B.Sc. (hons), and the Ph.D. in botany in 1992, 1995, and 2000, respectively.

Between 2000 and 2005 he was with Michigan State University, East Lansing, MI, USA, as a visiting research associate, where his passion for Arctic and functional ecological research and international scientific networking was established. He is presently an Associate Professor at the University of Texas at El Paso in the Department of Biology and the Environmental Science and Engineering Program, and he leads the Systems Ecology Lab. 


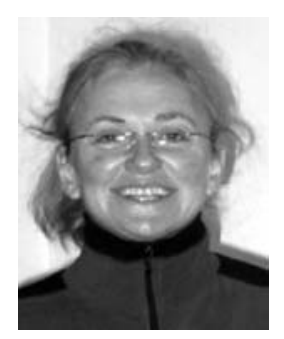

Petya K. Entcheva Campbell (M'99) received the B.S. degree in forest engineering and silviculture from the University of Forestry, Sofia, Bulgaria, the M.S. degree in forest ecology from the University of Massachusetts, Amherst, MA, USA, and the Ph.D. degree in forest analysis/remote sensing from the University of New Hampshire, Durham, NH, USA.

Currently she is a Research Assistant Professor at the Joint Center for Earth Systems Technology, University of Maryland Baltimire County (UMBC). She is affiliated with the Department of Geography and Environmental Systems at UMBC, where she has taught GES481/681 undergraduate/graduate classes in "Remote sensing for environmental applications". She is a research associate at the Biospheric Sciences Laboratory at NASA Goddard Space Flight Center (GSFC), Greenbelt, MD, USA. Her research focuses on remote sensing of vegetation bio-physical parameters and function for assessing ecosystem processes and dynamics, conducting spectral reflectance and fluorescence analyses and using satellite, airborne, field and laboratory measurements. At GSFC she contributes to the research of spectral bio-indicators of vegetation function, and participates in the Mission Science team for the Earth Observing 1 (EO-1).

Dr. Campbell is a member of American Society for the Advancement of Science (AAAS), Geoscience and Remote Sensing Society (IEEE GRSS), International Association for Landscape Ecology (IALE), and the Society of American Foresters (SAF), and has previously served as the Technical Secretariat for the WGCV/CEOS.

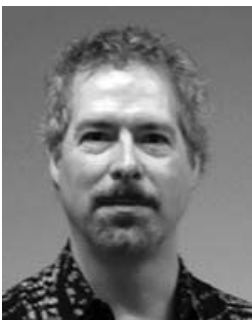

David R. Landis received the B.S. degree in computer programming from Elizabethtown College, Elizabethtown, PA, USA.

$\mathrm{He}$ is a Senior Programmer with the Biospheric Sciences Laboratory (Code 618) at NASA/GSFC, Greenbelt, MD, USA. He is currently working on the Earth Exploring One (EO-1) satellite. He has over 25 years of experience as a contract staff programmer-analyst at GSFC. He has experience working for MODIS, Landsat, and EO-1. His information technology experience is extensive, having worked on data systems and data publication tasks for five large climatology projects (FIFE, BOREAS, BOREAS Follow-on, SAFARI 2000, ISLSCP-2). $\mathrm{He}$ has considerable programming skill and Web designer experience. He also has significant science background, and has worked with scientists in many disciplines.

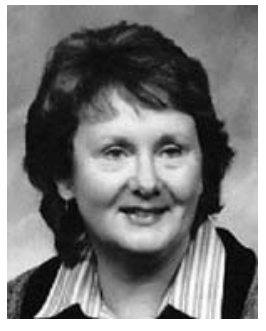

Elizabeth M. Middleton received the B.S. degree in zoology from the University of Maryland in 1967, the M.S. degree in ecology from the University of Maryland in 1976, and the Ph.D. degree in botany from the University of Maryland in 1993.

She is a Senior Scientist with the Laboratory for Biospheric Sciences at NASA/GSFC, Greenbelt, MD. She is currently the Mission Scientist for the Earth Exploring One (EO-1) satellite and the GSFC lead for the NASA HyspIRI satellite concept development.

Dr. Middleton recently received in 2011 a Career Achievement Award from the Hydrospheric and Biospheric Sciences Laboratory at GSFC. She also received NASA Group Achievement Awards in 1983, 1994, 1995, and 2003, in addition to numerous Performance Awards. She has previously served, and is currently serving, as the Outside Observer on the Mission Advisory Group (2007-2009, 2011...) for a European Space Agency's Phase A satellite mission concept - the FLuorescence Explorer (FLEX). In addition, she was a member of NASA/GSFC Carbon Cycle Science Working Group (2000-2007) and the NASA representative to the US Federal Geographic Data Committee's Vegetation Subcommittee for many years. She leads a research team that studies vegetation spectral bio-indicators of plant stress and photosynthetic function, including plant fluorescence. She is Associate Editor of the Journal of Applied Remote Sensing. 